\title{
Assessment of Deaf Children's Knowledge and Practice Regarding Car Accidents Protection
}

\author{
Laith Mahmoud Alosufe ${ }^{1}$, Hekmat Ebrahim Abd El-Kareem ${ }^{2}$ \& Asmaa Abed Al-Aziez Mohamed ${ }^{3}$. \\ 1. Assistant lecturer, Faculty of Nursing and Health Science, Al-Hussein Bin Talal University, Hashemite \\ Kingdome Of Jordan. \\ 2. Professor of Pediatric Nursing, Faculty of Nursing, Assiut University, Egypt. \\ 3. Assistant Professor of Pediatric Nursing, Faculty of Nursing, Assiut University, Egypt.
}

\begin{abstract}
Background: Hearing impaired children have static and dynamic balance disabilities and that their physical adaptation is lower than that of nondisabled peers. Aim: to assess knowledge and practice for deaf children's regarding car accidents protection. Design: descriptive research design was used in this study. Subjects: The study sample composed of 69 school age and adolescent deaf children. Setting: The study was conducted at The Holy Land Institute for the Deaf, Jordan - Salt governorate. Tools of data collection: An interview questionnaire was designed by researcher to collect data related to characteristics of deaf children, characteristics of deaf children hearing, and knowledge and practice of deaf children about protection from car accident. Results: Deaf children's age ranged between 12- 18 years, males are more affected with hearing disorder than females and their academic achievement was good (41\%). The majority lived in dormitories at school. Deaf children' knowledge and practice scores protection from car accidents were unsatisfactory. Conclusion: Deaf children's knowledge and practice regarding protection from car accidents were unsatisfactory. The age at which deafness began, degree of deafness were not affecting on the studied deaf children' academic achievement .Recommendation: The recommendation was suggested that ongoing in-service educational program for deaf children to improve their knowledge and practice regarding protection from car accidents.
\end{abstract}

\section{Keywords: Deaf children, Knowledge \& Practice, Protection, Car Accidents.}

\section{Introduction}

Hearing is one of the human five senses. It gives access to sounds in the world around. Hearing loss can have a major impact on the life of a child and his family. Because language and communication develop so rapidly during the first 3 years of life, an undetected hearing loss is likely to interfere with a child's speech, language and communication with others. Hearing loss also can result in learning problems that affect a child's performance at school (Loss, 2006).

Disabling hearing loss refers to hearing loss greater than 40 decibels $(\mathrm{dB})$ in the better hearing ear in adults (15 years or older) and greater than $30(\mathrm{~dB})$ in the better hearing ear in children $(0$ to 14 years)(WHO, 2012).

Deafness may be viewed as a condition that prevents an individual from receiving sound in all or most of its forms. In contrast, a child with hearing loss can generally respond to auditory stimuli, including speech (Individual with Disabilities Educational Act (IDEI), 2013)

About 10. 000 infants are born in the United States every year with sensorineural deafness. While the incidence of sensorineural deafness is similar in most high-income countries and is higher in some lowincome countries, the parents have normal hearing and no knowledge of sign language. So they should learn a sign language and begin to communicate with their child by using that sign language (Mellon, et al., 2015).

Over $5 \%$ of the world's population - 360 million people - has disabling hearing loss (328 million adults and 32 million children). Half of all cases of hearing loss are avoidable through primary prevention (WHO, 2015).

Globally, 150 million children aged 0-18 are estimated to be living with a disability, the majority of those disabled children live in low and middleincome countries (Devries, et al., 2014).

In Egypt the number of disabled persons is $0.7 \%$ of the total population. Mental retardation resembles (22.6\%), while blindness, deafness, dumbness, and other disabilities resemble $(9.5 \%)$, (3.5\%), (2.5\%), $(6.5 \%)$, and $(55.4 \%)$ respectively. In Assiut governorate the disabled children aged between 5 to15 years represent $6.5 \%$. (The Census of Population \& Housing Condition, 2006).

In Jordan, hearing disabilities is located in second place in terms of prevalence after mental disabilities, as the number of those who suffer from hearing disability is about 3,500 people, representing $1 \%$ of the total disabilities (Graby, 2015).

Unbalanced children with vestibular dysfunctions may have problems with walking and may exhibit manifestations such as falling over, dizziness, vertigo 
and bumping into things, making it harder for them to acquire the abilities that are typical of their age group, such as riding a bicycle, skipping and even using the equipment at children's playgrounds precaution of car accident (Article, 2012).

Many children are killed when adults back over them with a car. In addition, there are many cases of deaths of young children who were left unattended by an adult in a car. So Children should be "street smart" as soon as they are ready to walk outdoors. Preschoolers are old enough to learn simple traffic safety concepts but will need reminders and practice to help them remember and carry out the safe behavior every time. It is not until children reach school age ( 7 to 11 years old) that they will begin to consistently remember and practice complex traffic safety rules (Zamani, et al., 2007).

Hearing impaired children's posture indicates a process of compensation for lack of auditory. Studies have shown that hearing impaired children have static and dynamic balance disabilities and that their physical adaptation is lower than that of nondisabled peers. Gross motor functions are fundamental to balance and gait while delayed motor development may affect balance and gait in children with hearing impairment (Uysal, et al., 2010).

At school, children may be exposed to a number of risky situations in classrooms, on the playground during recess, or on the sports field during physical education or organized athletics. By law, schools must expose children with disabilities to a range of school activities that promote their physical, emotional, and social development and prepare them for independent living. Individual educational program (IEPs) and school-wide environmental assessments are mechanisms through which injury prevention strategies can be introduced, maintained, and programmed in school for the greater safety of children with disabilities (Ramirez, et al., 2010).

Fundamentally, the fulfillment of the basic human rights of children with disabilities depends on genuine acceptance by their families, communities, societies and governments as equal citizens. It is worth noting that the majority of existing laws and policies on disability are not only outdated, but also don't prioritize issues of disability (The African Child Policy Forum, 2011).

The significance of the current study lies in the fact that researches focusing on programs to prevent car accidents in deaf children were lacking so the researcher conducted this study to explore the effect of program on protection from car accident as a means of safety during activity of daily living.

\section{Aim of the study}

To assess deaf children's knowledge and practice regarding car accidents protection

\section{Research question}

What is the level of deaf children knowledge and practice regarding car accident protection.

\section{Research Design}

A descriptive research design was used in this study

\section{Setting}

The study was conducted at The Holy Land Institute for the Deaf, Jordan - Salt governorate.

The Holy Land Institute for the Deaf

(مؤسسة الأراضي المقدة للصم) is a non-profit foundation located in Salt, Jordan, north of Amman, that provides educational and rehabilitation services for people with hearing impairment. The facility serves approximately 140 male and female students, mostly Jordanian, from the age of 3 to 20. Thirty five teachers who are specialists on deafness work in that institute.

The institute also provides audiology service and hearing aids, and the outreach program tests children in refugee camps. Due to the location of the school, which is close to traffic crisis, traffic lights and crowded places, we had to present this program to this category of students.

\section{Subjects}

The study sample composed of 69 school age and adolescent deaf children.

\section{Tool of data collection}

Questionnaire sheet: it was used for collecting the data of the study. It consists of four parts:-

Part I: It was designed to assess characteristics of deaf children such as: age, sex, birth order, and academic achievement (Excellent $(>=85.0 \%)$, very $\operatorname{good}(>=75.0), \operatorname{good}(>=65.0)$, passed $(>=50.0 \%)$ and failed $(<50.0 \%)$ according to guidance of laws of Jordanian Ministry of Education).

Part II: Characteristics of children's hearing is divided into

The age at which deafness began (at birth, at school), family history ( positive or negative), degree of hearing impairment (No impairment, slight impairment, moderate impairment, severe impairment and profound impairment), amplification (hearing aid, cochlear implant, no usage of amplification) according to Graham, (2014) who used WHO report grade of the informal working group of deafness and hearing impairment program.

Part III: It was designed to determine deaf children' knowledge about protection from car accident including:

Definition of car accidents and injuries, causes of car accidents, traffic laws, and traffic lights such as light signal, pedestrian light sign, traffic cop, sidewalk, pedestrian walkway, footbridge, pedestrian tunnel, 
signal stopped, turn right, turn left, run over, street parts, safe transit places, risk transit places, places to play

This information is gained from Central Traffic Management / Jordan General Security Directorate, 2016.

\section{Scoring system}

The scoring system used for knowledge part was divided into three groups of items. In the group one which included definition of injuries, define car accident, light signal, pedestrian light sign, traffic cop, sidewalk, pedestrian tunnel, signal stopped, turn right, turn left and run over; each correct answer received 3 score and each wrong answer or a "don't know" one got zero score. In the group two which included four causes of car accident; the correct answer received 2 score and the wrong answer got zero score. Regarding the group three which included items of street parts, safe transit place, risk transit places and places to play, each correct answer accounted for 1 score and each wrong answer received zero score. The total knowledge score (65) was judged as the following: unsatisfactory $<34$ and satisfactory $>=34$.

Part IV: It was designed to assess deaf children's practice about protection from accidents including group of skills needed to prevent car accidents and how to decrease exposure to these accidents such as rules and etiquette of walking on the sidewalk, rules of safe passage for roads, etiquette of riding cars and ways to avoid accidents run over.

\section{Scoring system}

The Scoring system used for practical part was that (done $=2$ score and every wrong answer or a "not done" one =zero score).

The total practical score (50) was judged as the following: unsatisfactory $<25$ and satisfactory $\geq 25$.

\section{Method}

Study was conducted through two phases:

\section{Phase (1): preparatory phase}

1. Permission was obtained from head of The Holy Land Institute for the Deaf through written letter from the Nursing College at Assuit University.

2. The tool for data collection after reviewing the related literature was developed.

3. Pilot study was conducted on $10 \%$ of sample (7children) in a selected setting to evaluate the applicability \& clarity of the tool. According to this pilot study, the required modifications were made and excluded from the study.

4. The validity of the tool was obtained by community and pediatric experts of Nursing College at Assiut University.

5. The stability reliability of the tool was investigated by test-retest reliability method which indicated by correlation coefficient (coefficient of stability). The correlation between the test and the retest over a 2-week period was estimated $(r=0.68, P<0.001)$. Test-retest reliability demonstrated that the correlation of all domains were very significant. In addition to the internal consistency reliability of tool was investigated by split-half procedure (coefficient alpha or Cronbach's alpha). The correlation coefficient was 0.89 .

6. The feasibility of study was checked during pilot study.

Phase (2): implementation phase:

1. Permission for participation was obtained from the children by sign language.

2. After obtaining a sign consent by deaf children to participate in the study, and reassuring him about the strict confidentiality of any obtained information, and that the study results would be used only for the purpose of research.

3. The questionnaire sheet was administered to answer the questions included in the parts 1,2 and 3.

4. Then, the studied deaf children were divided into five groups.

5. The five groups of the studied deaf children were taken to Traffic Garden designed by researcher to assess the practice skills about protection of car accidents and trick the observational checklist included in part 4.

6. The five groups of the studied deaf children were then taken to Real Street to complete the observational checklist included in part 4.

\section{Ethical consideration}

The research proposal was approved from Ethical Committee of The Faculty of Nursing at Assuit University; confidentiality and privacy of the study were asserted. Consent was taken from the deaf children's parents. Clarification of the nature and the aim of the study was done in initial interview with each deaf child by the help of teachers, with an emphasis that the study yields no harm to the children. The children had the right to refuse to participate in the study without any rational.

\section{Statistical design}

The Statistical Package for Social Sciences (SPSS) software (Version 16) was used for analysis. The categorical data such as age, gender, the age at which deafness began family history, birth order, academic achievement, and child residence, degree of deaf and used of amplification are presented as frequency and percentage.

\section{Results}

The results of the current study were presented in three parts: 
Part One: - This part concerned with characteristics and hearing data of the studied deaf children. Tables $(1,2)$

\section{Results}

Part one: Characteristics of the studied deaf children.

Table (1): Characteristics of the studied deaf children.

\begin{tabular}{|l|c|c|}
\hline \multirow{2}{*}{ Characteristics } & \multicolumn{2}{c|}{ Deaf children (no=69) } \\
\cline { 2 - 3 } & No. & \\
\hline Age & & 36.2 \\
\hline School & 25 & 63.8 \\
\hline Adolescent & 44 & 52.2 \\
\hline Sex & & 47.8 \\
\hline Male & 36 & \\
\hline Female & 33 & 24.6 \\
\hline Birth order & & 17.5 \\
\hline $1^{\text {st }}$ & 17 & 24.6 \\
\hline $2^{\text {nd }}$ & 12 & 33.3 \\
\hline $3^{\text {rd }}$ & 17 & \\
\hline $4^{\text {th }}$ & 23 & 24.6 \\
\hline Academic achievement & & 26.1 \\
\hline Excellent & 17 & 40.6 \\
\hline Very good & 18 & 8.7 \\
\hline Good & 28 & 91.3 \\
\hline Pass & 6 & 8.7 \\
\hline Child Residence & & \\
\hline Dormitories at school & 63 & \\
\hline With the family & 6 & \\
\hline
\end{tabular}

Table (2): Characteristics of hearing impairment of the studied deaf children.

\begin{tabular}{|l|c|c|}
\hline \multicolumn{1}{|c|}{ Characteristics of hearing impairment } & \multicolumn{2}{c|}{ Deaf children(no=69) } \\
\cline { 2 - 3 } & No. & \\
\hline The age at which deafness began & & 79.7 \\
\hline At birth & 55 & 20.3 \\
\hline School & 14 & 69.6 \\
\hline Family history & & 30.4 \\
\hline Positive & 48 & \\
\hline Negative & 21 & 5.8 \\
\hline Degree of hearing impairment & & 27.5 \\
\hline Slight impairment & 4 & 40.6 \\
\hline Moderate impairment & 19 & 26.1 \\
\hline Severe impairment & 28 & \\
\hline Profound impairment & 18 & \\
\hline Usage of amplification & & \\
\hline Hearing aid & 28 & \\
\hline Cochlear implant & 22 & \\
\hline None & 19 & 27.9 \\
\hline
\end{tabular}


Part two: Total knowledge of studied deaf children about protection from car accidents. Table (3): level of the studied deaf children's total knowledge about car accidents protection.

\begin{tabular}{|l|c|c|}
\hline \multicolumn{1}{|c|}{ Total knowledge } & No. & \% \\
\hline Satisfactory & 20 & 29 \\
\hline Unsatisfactory & 49 & 71 \\
\hline $\bar{X} \pm$ SD & \multicolumn{2}{|c|}{$26.55 \pm 16.95$} \\
\hline
\end{tabular}

$\bar{X} \pm S D=$ mean \pm standard deviation

Part three: Total practice of studied deaf children about protection from car accidents Table (4): level of the deaf children's total practice about car accidents protection.

\begin{tabular}{|l|c|c|}
\hline \multicolumn{1}{|c|}{ Score of practice } & No. & \% \\
\hline Satisfactory & 24 & 34.8 \\
\hline Unsatisfactory & 45 & 65.2 \\
\hline $\bar{X} \pm$ SD & \multicolumn{2}{|c|}{$21.72 \pm 6.19$} \\
\hline
\end{tabular}

Table(1): Showed that; about two- thirds of the studied children were adolescents (63.8\%). More than $52.2 \%$ were male. Third birth order was represented by $33.3 \%$ of the studied children. Their academic achievement was good in $40.6 \%$ of the studied children. The majority of the studied children lived in dormitories at school (91.3\%).

Table (2): Showed that; the majority of the studied children began deafness at birth (79.7\%). The most of the studied children had positive family history (69.6). Severe and profound impairment were found in $40.6 \%$ and $26.1 \%$ respectively .Less than a half $(40.6 \%)$ used hearing aid and third of them had cochlear implant.

Table (3): Illustrated level of studied deaf children's knowledge about car accidents, the majority had unsatisfactory knowledge (71\%) with $26.55 \pm 16.95$ mean score.

Table (4): Illustrated level of studied deaf children's total practice scores about car accidents. The majority in pre educational program had unsatisfactory practice scores $(65.2 \%)$ with total mean practice score $21.72 \pm 6.19$.

\section{Discussion}

Hearing is the ability to perceive sound. A person suffering from hearing impairment has difficulty in perceiving or identifying sound clearly due to auditory problems. Impairment could be unilateral or bilateral (Dankbaar \& Van Zanten, 2008).

The aim of this study was to assess deaf children's knowledge and practice regarding car accidents protection.

As for the studied children's age, it was found that the high incidence of deaf children aged between 12- 18 years. This finding disagrees with the results of the research which is entitled the education of deaf and hard of hearing children in Ireland which was published by Tobergte \& Curtis, (2013) who found that one third of hearing loss children aged between 5-10 years within school age, and also with (Gheysen \& Waelvelde, 2007)who investigated the impact of a cochlear implant (CI) on the motor development of deaf children with and without cochlear implants as the studied deaf children aged from 2 - 9 years. (Abdelghaffar \& Elshazly, 2011) applied their project on 45children (21 males and 24 females) between 5 and 6 years of age too.

As for the studied deaf children gender, in the present study results showed that males are more affected with hearing disorder compared to females. This finding is in agreement with a study carried out by(Tobergte \& Curtis, 2013)who found a higher prevalence of hearing disorder in males than in females. But this result disagrees with the results of the research which is entitled demographic and hearing related variables for production of disabling hearing impairment which was carried out by Ahmed \& Tsiga-ahmed, (2015) who studied 58 patients with hearing disorder and found that hearing disorder was more prevalent in females as compared to males According to Dankbaar \& Van Zanten, (2008) studied which is entitled developmental disorders series, hearing impairment, child assessment service the academic performance was affected due to difficulty in receiving the correct messages. If a child does not hear the teacher well, she may not follow instructions well, and be considered either a 'behavior problem' or a withdrawn student. This finding was in agreement with the present study regarding academic achievement of studied deaf children were good $(40.6 \%)$.

This finding also disagreed with the finding of the study which is entitled increasing early reading skills in young signing deaf children using shared book reading which was carried out by Andrews et al., (2017) in hearing loss and its implications for 
learning and communication which illustrated that children may have; lower scores on achievement and verbal IQ tests, poor reading and spelling performance, greater need for enrollment in special education or support classes, and lower performance on measures of social maturity.

Although the deafness playing very important impact on the educational process and students academic achievement but I think some time students with disability achieve more score and high level of IQ.

The results of the present study showed that the majority, of the studied deaf children had settled in dormitories at school. This finding disagree to the results which is entitled raising awareness of deaf students and their school care- givers about first aids intervention in medical emergencies which was published by Hassan \& Abd-Elraouf, (2010) who found that the studied deaf children had lived with their families. This may be due to in sample characteristics and disease severity in that study.

Regarding the age at which deafness began, three quarters of the studied deaf children had hearing loss at birth. This agree with the findings of academic and social adjustment among deaf and hard of hearing college students in Taiwan carried out by Roberts et al., (2013)who found that more than one third of hearing loss onset of studied deaf children started at birth, also this finding is consistent with result of Tobergte \& Curtis,(2013)who found that more than half of the studied deaf children were diagnosed as hearing loss onset at birth.

On the other hand, results of this study emphasized that severe impairment was the most degree of hearing impairment in studied deaf children. This finding agrees with the results of study entitled pragmatic language impairment which was carried out Bishop, (2014) whose results revealed that the degree of deafness was severe hearing impairment. But Roberts et al., (2013) disagree with the finding of the present study, as more than half studied deaf children had profound impairment.

As regard using amplification in children with hearing impairment, the results of the present study indicated that more than one third of deaf children used hearing aids. This finding agrees with the results of the study carried out by Roberts et al., (2013)who found that there was a raised incidence of hearing aids used in children with hearing impairment.

According to the present study results, the majority of studied had unsatisfactory knowledge about car accidents prevention, but the Dacota (2013) in his study entitled children in road traffic, the impact of road traffic on the psychomotor skills development was found that the children who have disability and psychomotor skills deficiency are increasingly risked to traffic crashes. This finding unsatisfactory knowledge about car accidents prevention related to decrease focusing and importance school education curriculum in Jordan on car accident and how to prevent it.

Based on the result of current study, the majority of studied deaf children had unsatisfactory practice total scores regarding car accidents prevention. This result is in accordance with that of Taylor et al., (2017) study which entitled promoting positive youth development through school based social and emotional learning interventions who found that children's road safety behavior is not sufficient and discusses the size of the problem and the causes and consequences of deafness and hearing impairment. It emphasizes the inadequate state of practice of this subject in developing countries and the importance of collecting valid data. In addition describes the public health route to prevention of deafness and hearing impairment, especially through primary ear and hearing care for prevention of deafness and hearing impairment.

\section{Conclusion}

Based on the results of the current study, it can be concluded that

The deaf children's knowledge and practice regarding car accidents were unsatisfactory.

\section{Recommendations}

Based on the results of this study, the following recommendations are suggested

1. Design educational program in all private and governmental schools at Jordan to increase knowing about protect of deaf child from car accident.

2. Future researches should be done on large sample of children in different settings focusing on the outcome of children.

3. In-service training programs for teacher should be provided to increase knowledge and skills about car accident to reduce incidence of accidents among deaf children.

\section{References}

1. Abdelghaffar H., \& Elshazly M., (2011): Cochlear implants in children with vestibular hypofunction. Egyptian Journal of Ear, Nose, Throat andAlliedSciences, 12(1):49-52.

2. Ahmed A., \& Tsiga-ahmed F., (2015): Demographic and hearing related Variables for prediction of disabling hearing impairment: A Community Based Survey,(March 2013) ,Pp: 94-101. Accessed at :http://doi.org/10.9734/IJTDH/2015/16822.

3. Andrews, J., Liu, H., Liu, C., Gentry, M., \& Smith, Z., (2017): Increasing early reading 
skills in young signing deaf children using shared book reading: a feasibility study. Early child development and care, 187(3-4):583-599.

4. Article O., (2012): Balance and gait evaluation: comparative study between deaf and hearing students, Vol 30, No (3), 385-391.

5. Bishop, D., (2014): Pragmatic language impairment: A correlate of SLI, a distinct subgroup, or part of the autistic continuum?. In Speech and language impairments in children (pp. 113-128). Psychology Press.

6. Central traffic management / Jordan general security directorate. (2016): traffic rules and the safety of school children,To my School Saftey.

7. DaCoTa (2013): children in road traffic, the impact of road traffic on the psychomotor skills development, Project co-financed by the European Commission Directorate General for Mobility and Transport, Pp23 - 24

8. Dankbaar W., Van Zanten, M., (2008): Developmental Disorders Series ,Hearing impairment, Child Assessment Service, Department of Health Nederlands Tijdschrift Voor Geneeskunde, Pp:2-4.

9. Devries A., Carr G., Davis A., (2014): community Ear \& Hearing health, Early detection of hearing loss in newborn and preschool children, vol 11 Issu (15), Pp: 1-12.

10. Graby, S., (2015): Neurodiversity: Bridging the gap between the disabled people's movement and the mental health system survivors' movement. Madness, distress and the politics of disablement, 231-244.).

11. Gheysen, F., \& Waelvelde, H., Van, (2007): Motor Development of Deaf Children With and Without Cochlear Implants, (2006). http://doi.org/10.1093/deafed/enm053.

12. Graham, N., (2014): Background paper for fixing the broken promise of education for all, children with disability,Pp:1-12.

13. Hassan R., \& Abd-Elraouf S., (2010): Raising A warness of Deaf Students and their school care -Givers about First Aids Intervention in Medical Emergenceis, Journal of American Science, Vol 6, No (12). Retrieved at: http://www.americanscience.org.

14. Loss, H., (2006): Birth Defects \& Genetics : Hearing Loss Birth Defects \& Genetics : Hearing Loss Page 2 of 4, 4-7.

15. Mellon, N., Niparko J., Rathmann C., Mathur G., Humphries T., Lantos,D., (2015), Should All Deaf Children Learn Sign Language? Pediatrics, 136(1), 170-176. http://doi.org/10.1542/peds.2014-1632.

16. Ramirez M., Fillmore E., Chen A., \& Peek-
Asa C., (2010): A Comparison of School Injuries between Children with and without Disabilities. Academic Pediatrics, 10(5), 317322.

17. Roberts S., (2013): First Aid Afloat, Children and Infant's the Choking Child, Lippincott Williams \&wilkins,1st Ed, chapter 7;Pp:101 105

18. Taylor, R., Oberle, E., Durlak, J., \& Weissberg, R., (2017): Promoting positive youth development through school-based social and emotional learning interventions: A meta-analysis of follow-up effects. Child development, 88(4), 1156-1171.

19. The African Child Policy Forum (2011): Violence against Children with Disabilities in Africa; available at(www.africanchildforum.org.

20. The census of population and housing condition, (2006): Arab Republic of Egypt, Egyptian central agency or public mobilization and statistics, available at: (http://www.capmas.gov.eg/database.aspx?pare ntid $=1782 \&$ free $=1$ )

21. Tobergte, D., \& Curtis, S., (2013): The Education of Deaf and Hard of Hearing Children in Ireland November. Journal of Chemical Information and Modeling, 53(9), 1689-1699. http://doi.org/10.1017/CBO9781107415324.004

22. WHO, (2012): WHO Global Estimates on Prevalence of Hearing loss.

23. Zamani A., Rahman, Anderson B., Evinger S., (2007): Health and Safety in the Child Care Cetting Prevention of Injuries, A Curriculum for the Training of Child Care Providers, Motor Vehicle, Transportation and Pedestrian Safety, 2nd ed, Pp:-27-37. 